\title{
Pengujian Black Box pada Aplikasi Pertokoan Minimarket Menggunakan Metode Equivalence Partitioning
}

\author{
Rizky Prasetyo Adi ${ }^{1}$, Yoga Koswara ${ }^{2}$, Jajang Tashika ${ }^{3}$, Yuliana Devi ${ }^{4}$, Aries Saifudin ${ }^{5}$ \\ Teknik Informatika, Universitas Pamulang, Tangerang Selatan, Indonesia \\ e-mail: ${ }^{1}$ rizkyprasetyoadi707@gmail.com, ${ }^{2}$ yoga123@gmail.com, ${ }^{3}$ jajang@ gmail.com, \\ 4yulianaaa@gmail.com, ${ }^{5}$ aries.saifudin@unpam.ac.id
}

Submitted Date: Maret $22^{\text {nd }}, 2020$
Revised Date: April 08 ${ }^{\text {th }}, 2020$

\begin{abstract}
Quality measurements in software are currently required before the software will be used by users. This aims to determine the weakness of the system so that the data generated can match the data entered after the data is executed. This method focuses on data entry, system display, memory usage, and data execution speed so that if the input data does not match what is expected then the system fails.In implementation problems often arise when testers are never sure whether the software being tested has actually passed the test. This happens because there may be several execution paths that have never been tested. The minimarket stock management application will be tested using a black box test where this test is only intended to see if the program matches the function desired by the program without knowing the program code used. To generate test case designs automatically in black box method software testing with the equality.technique partition technique.
\end{abstract}

Keywords: Aplication; Testing; BlackBox; Equality Partition; Minimarket Management Stock Opname System

\begin{abstract}
Abstrak
Pengukuran kualitas dalam perangkat lunak saat ini diperlukan sebelum perangkat lunak akan digunakan oleh pengguna. Ini bertujuan untuk mengetahui kelemahan sistem sehingga data yang dihasilkan dapat cocok dengan data yang dimasukkan setelah data dieksekusi. Metode ini berfokus pada entri data, tampilan sistem, penggunaan memori, dan kecepatan eksekusi data sehingga jika data masukan tidak sesuai dengan yang diharapkan maka sistem gagal.Dalam implementasi masalah sering muncul ketika para penguji tidak pernah yakin apakah perangkat lunak yang diuji telah benar-benar lulus tes. Ini terjadi karena mungkin ada beberapa jalur eksekusi yang belum pernah diuji.. Aplikasi manajemen stok opname minimarket akan diuji menggunakan pengujian black box di mana tes ini hanya dimaksudkan untuk melihat apakah program tersebut sesuai dengan fungsi yang diinginkan oleh program tanpa mengetahui kode program yang digunakan. Untuk menghasilkan desain kasus uji secara otomatis dalam pengujian perangkat lunak metode kotak hitam dengan teknik equivalence partition.
\end{abstract}

\section{Keywords: Aplikasi; Pengujian; BlackBox; Equivalence Partition; Sistem Management Stock Opname} Minimarket

\section{Pendahuluan}

Untuk menjamin software yang dihasilkan telah bebas dari kesalahan umumnya dilakukan dengan pengujian yang merupakan tahapan paling mahal dalam pengembangan software (Saifudin \& Yulianti, 2020). Pengujian Perangkat Lunak Pengujian adalah proses eksekusi program untuk menemukan kesalahan. Pengujian perangkat lunak (testing) merupakan bagian terpenting dalam pengembangan perangkat lunak (software engineering). Pengujianya atau uji coba tersebut bertujuan untuk mencari sebanyak mungkin kesalahan (bug error) dan menemukan kesalahan yang sebelumnya tidak ditemukan, serta untuk mengurangi resiko yang terkandung dalam suatu sistem komputer. Suatu pengujian dikatakan 
berhasil apabila menemukan kesalahan-kesalahan yang belum terdeteksi. Secara umum pengujian dilakukan untuk menentukan perbedaan antara hasil yang diharapkan dengan hasil sebenarnya. Pengujian pada sebuah program penting untuk dilakukan guna memeriksa semua kesalahan yang ada pada program tersebut agar tidak menimbulkan hal-hal yang merugikan pada saat digunakan (Ningrum, Suherman, Aryanti, Prasetya, \& Saifudin, 2019).

Pengujian yang sukses adalah pengujian yang mengungkap semua kesalahan yang belum pernah ditemukan sebelumnya. Hal yang perlu diperhatikan dalam melakukan pengujian adalah penguji harusnya dapat mendapatkan kesalahan yang mungkin sebelumnya tidak terdeteksi dan dikatakan berhasil pengujian tersebut apabila dapat memperbaiki kesalahan tersebut sehingga kualitas software akan lebih baik. Dalam pengujian hal yang perlu diperhatikan adalah perancangan yang baik agar dapat dengan mudah menemukan kesalahan pada saat pengujian agar dapat diperbaiki dengan cepat sehingga dapat menghemat waktu dalam pengujian.

Tahapan pertama pada pengujian dengan menggunakan Blackbox Testing adalah mengidentifikasi masukan lalu diuji agar kita mengetahui letak kesalahannya. Pengujian menggunakan Blackbox Testing merupakan sebuah pengujian yang digunakan untuk melengkapi pengujian sebelumnya yaitu Whitebox Testing agar aplikasi yang kita buat memiliki kualitas yang baik serta waktu yang digunakan akan lebih efektif, sehingga dapat menguntungkan bagi perusahaan (Mustaqbal, Firdaus, \& Rahmadi, 2015).

Ada beberapa cara dalam menguji Black Box Testing salah satunya adalah mengunakan teknik Equivalence Partitions. Equivalence Partitions merupakan sebuah pengujian berdasarkan masukkan data pada setiap form yang ada pada sistem seleksi sales terbaik, setiap menu masukan akan dilakukan pengujian dan dikelompokkan berdasarkan fungsinya baik itu bernilai valid ataupun tidak valid (Hidayat \& Muttaqin, 2018).

Dalam penelitian ini terdapat beberapa tahapan, di mana diawali dengan menentukan Test
Case yang akan diuji, kemudian membaginya dengan beberapa partisi masukan dan keluaran. Hal ini dilakukan untuk mendapatkan dokumentasi pengujian (MZ, 2016).

\section{Metodologi}

Pengujian merupakan suatu proses pelaksanaan program yang bertujuan menemukan kesalahan dan memperbaikinya sehingga sistem dikatakan layak untuk digunakan (Nurudin, Jayanti, Saputro, Saputra, \& Yulianti, 2019). Pengujian sistem bertujuan untuk melihat apakah sistem yang telah dibuat sudah sesuai dengan tujuan awal pembuatan dan layak untuk dipergunakan. Pengujian pada sistem menggunakan metode Black Box, tujuannya untuk mengetahui bahwa bagian-bagian dalam system aplikasi telah benar menampilkan pesanpesan kesalahan jika terjadi kesalahan dalam pemasukan data. Black Box Testing sendiri merupakan pengujian yang dilakukan hanya mengamati hasil eksekusi melalui data uji dan memeriksa fungsional dari perangkat lunak (Krismadi, et al., 2019). Pengujian black box ini menitik beratkan pada fungsi sistem (Syaban \& Bunyamin, 2015).

Dalam penelitian ini akan dilakukan beberapa tahapan. Pada tahapan pertama diawali dengan menentukan Test Case perangkat lunak yang akan diuji dengan metode Equivalence Partition kemudian menginisialisasi standar grade partition masukan dan keluaran. Hal ini dilakukan untuk mendapatkan dataset berupa dokumentasi pengujian dengan metode Equivalence Partitions dan nilai tingkat efektifitas metode Equivalence Partitions.

Kemudian membuat batasan pengujian Equivalence Partitions, setelah membuat batasan pengujian, langkah selanjutnya adalah membuat model pengujian dari skenario pengujian dan hasil yang diharapkan, dan yang terakhir melakukan pengujian berdasarkan model yang dirancang. Hal ini dilakukan untuk mendapatkan data berupa dokumentasi pengujian dengan metode Equivalence Partitions dan nilai tingkat efektifitas metode Equivalence Partitions (Jaya, Gumilang, Wati, Andersen, \& Desyani, 2019). 


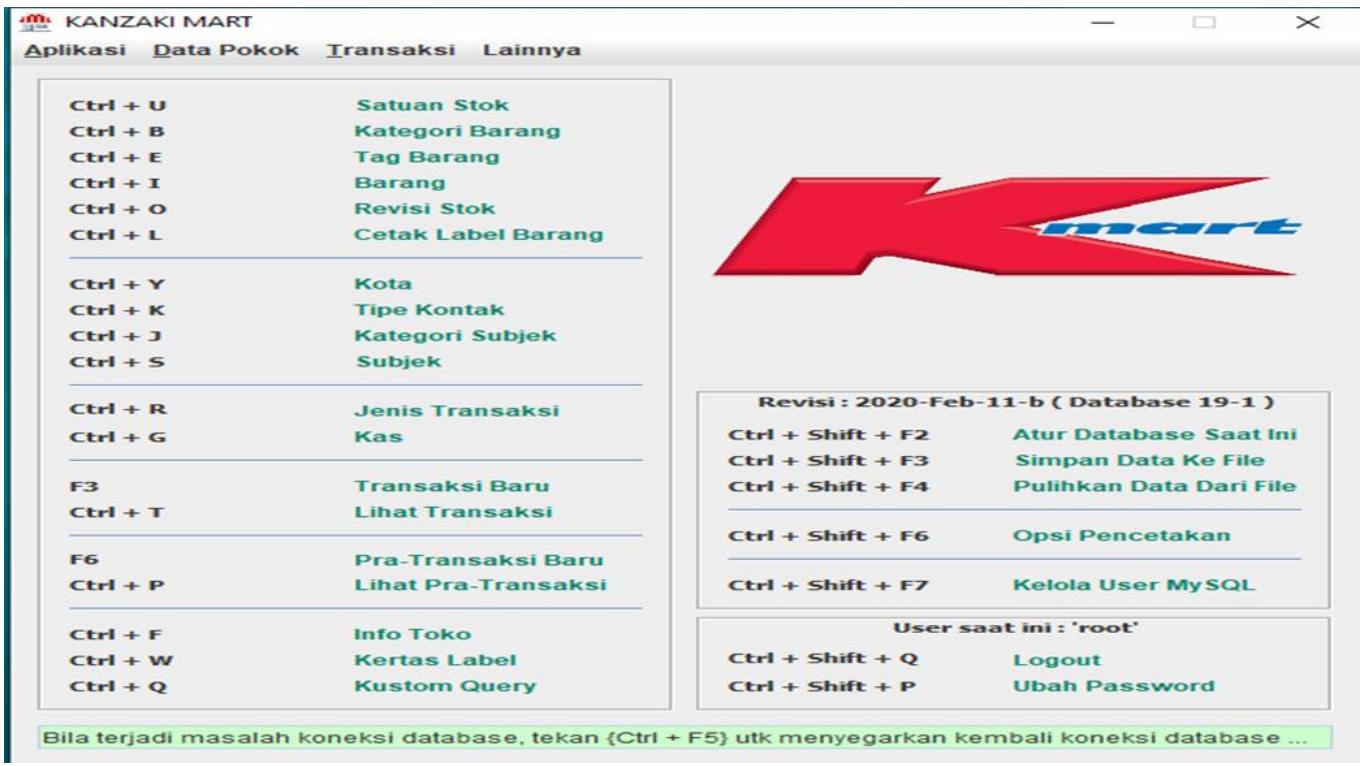

\section{Gambar 1 Form Home}

Berdasarkan form pada Gambar 1 terdapat beberapa rencana pengujian. Pada rencana pengujian sebelum membuka aplikasi, yaitu membuat akses user pada MySQL server dengan mengisi user : root \& password :root ,dan membuka aplikasi XAMPP terlebih dahulu . Apabila terdapat kesalahan pada pengisian user dan password pada MySQL server maka aplikasi ini tidak akan berjalan semestinya. Kemudian bisa dilihat pada gambar terdapat beberapa tombol otomatis untuk melihat info toko dengan menekan ctrl $+\mathrm{F}$, melakukan kustom query dengan menekan ctrl $+\mathrm{Q}$, mengatur ulang database saat ini dengan menekan ctrl + shift $+\mathrm{F} 2$, melakukan opsi pencetakan dengan menekan ctrl + shift + F6

Tabel 1 Rancangan Test Case Form Home

\begin{tabular}{|c|l|l|}
\hline Id & \multicolumn{1}{|c|}{ Deskripsi pengujian } & \multicolumn{1}{c|}{ Hasil yang diharapkan } \\
\hline A01 & $\begin{array}{l}\text { Mengisi nama user: root \& password: root } \\
\text { pada server MySQL }\end{array}$ & $\begin{array}{l}\text { Sistem menerima dan aplikasi akan terbuka, dan } \\
\text { menampilkan tampilan home }\end{array}$ \\
\hline AA02 & $\begin{array}{l}\text { Mengisi uma mer: } \\
\text { rizkyprasetyoadi707@ gmail.com\& pasword } \\
\text { apaajaboleh }\end{array}$ & $\begin{array}{l}\text { Sistem akan menolak dan menampilkan } \\
\text { pemberitahuan "nama user dan Password tidak } \\
\text { cocok", aplikasi tidak akan terbuka }\end{array}$ \\
\hline AA03 & $\begin{array}{l}\text { Mengkosongkan User dan Password pada } \\
\text { server MySQL lalu melaunching aplikasi }\end{array}$ & $\begin{array}{l}\text { Sistem akan menerima dan menampilkan } \\
\text { tampilan home, meskipun user \& pasword } \\
\text { dikosongkan }\end{array}$ \\
\hline
\end{tabular}




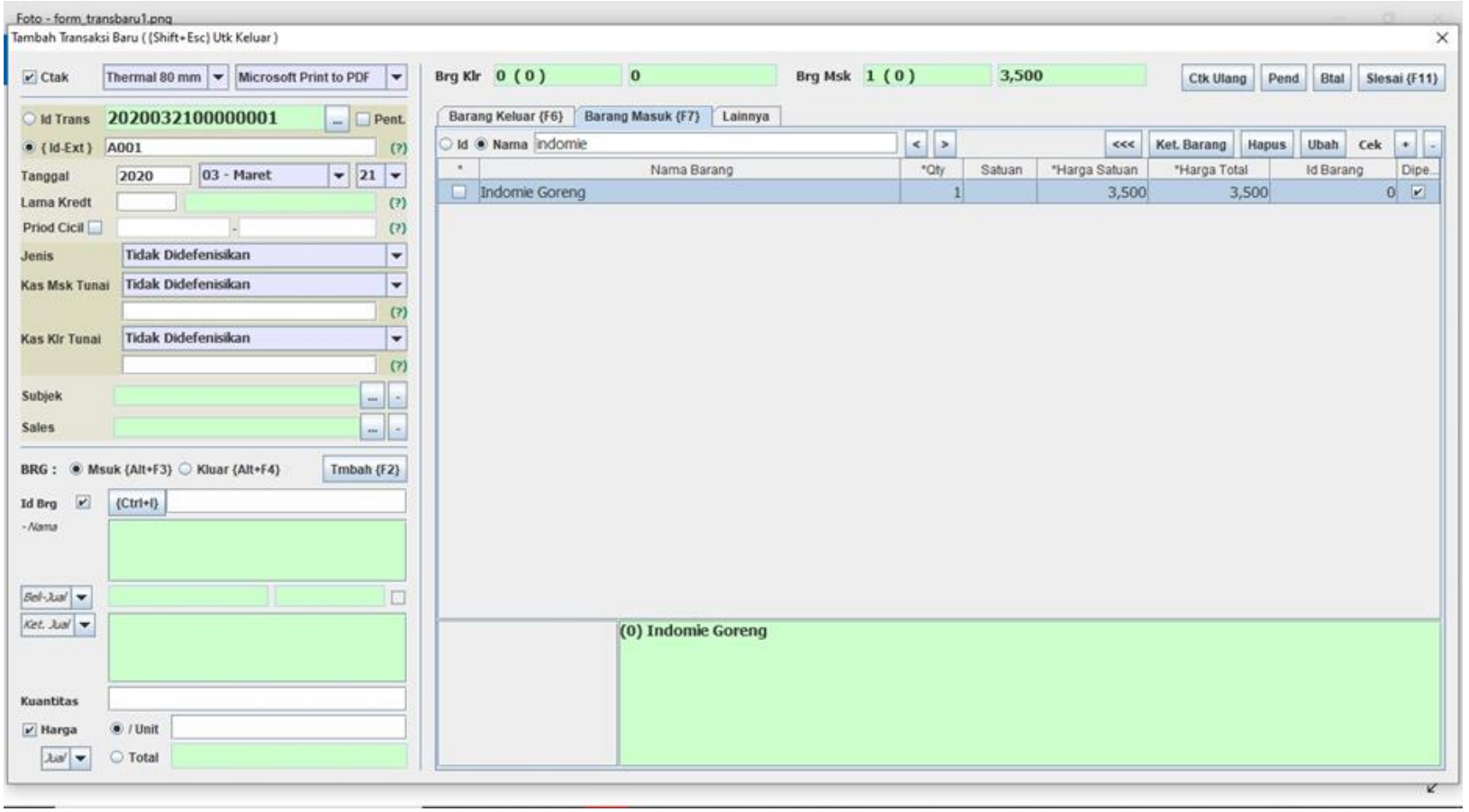

Gambar 2 Forn Transaksi

Berdasarkan form pada Gambar 2 terdapat rencana pengujian. Pada rencana pengujian form Transaksi product, Kita sebagai admin Dapat memasukkan produk pada transaksi masuk, transaksi keluar pada nota yang telah tersedia Id transaksi akan terisi secara otomatis sesuai tanggal pengisian formulir "20200321000001" jika diartiakan menjadi id transaksi 01, tanggal 21 bulan maret tahun 2020. Selanjutnya kia bisa melanjutkan pengisian dari mengisi id ext "A001, memilih jenis transaksi, mengisi subjek. Setelah Selesai kita tinggal menekan tombol Alt + F3 jika transaksi yang dimasukkan adalah transaksi barang masuk atau menekan tombpl Alt +F4 jika transaksi yang dimasukkan adalah transaksi barang keluar. Kita juga bisa menambah form baru(kosong) dengan menekan tombol F2.

Tabel 2 Rancangan Test Case Form Pembelian Barang

\begin{tabular}{|l|l|l|}
\hline Id & Deskripsi pengujian & Hasil yang diharapkan \\
\hline B001 & $\begin{array}{l}\text { Memasukkan transaksi barang masuk } \\
\text { dengan "Produk Indomie Goreng pada } \\
\text { kolom form, mengisi kuantitas barang } \\
\text { "1" \& harga jual satuan "Rp. 3500". }\end{array}$ & $\begin{array}{l}\text { Produk Indomie Goreng akan muncul pada } \\
\text { kolom transaksi masuk. Dengan harga jual satuan } \\
\text { "Rp. 3500" dan jumlah kuantitas "1". }\end{array}$ \\
\hline B002 & $\begin{array}{l}\text { Mengosongkan transaksi barang keluar } \\
\text { kedalam form yang sama dengan } \\
\text { sebelumnya. (masih 1 form) }\end{array}$ & $\begin{array}{l}\text { Produk Indomie Goreng tidak akan muncul pada } \\
\text { kolom transaksi keluar. Meskipun masih dalam 1 } \\
\text { form yang sama dengan transaksi masuk. } \\
\text { Kuantitas produk akan otomatis menulis angka } \\
\text { "0", pada transaksi barang keluar. }\end{array}$ \\
\hline
\end{tabular}




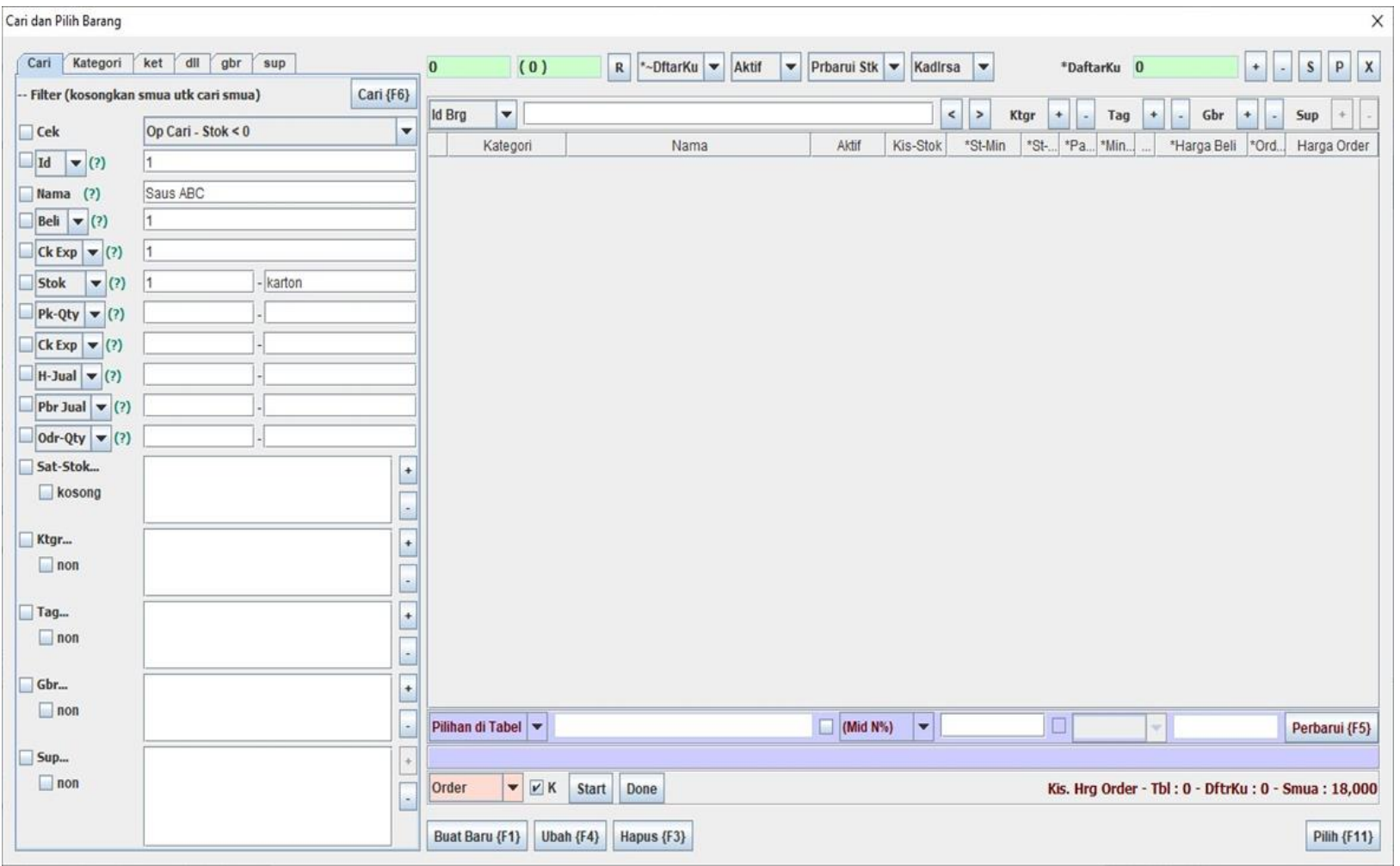

Gambar 3 Form Pencarian Produk

Berdasarkan form pada gambar 3 terdapat rencana pengujian pada form pencarian produk. Kita disini sebagai admin dapat mengisi produk yang ingin kita cari dan mengecek kembali apakah produk tersebut sudah ada di dalam form transaksi barang masuk atau form transaksi barang keluar. Dengan mengisi "Id","Nama Produk","Harga Beli","Stock","'Harga jual",,"Order Quantity".

Tabel 3 Rancangan Test Case Form Pencarian Produk

\begin{tabular}{|c|c|c|}
\hline Id & Deskripsi Pengujian & Hasil yang Diharapkan \\
\hline $\mathrm{C} 001$ & $\begin{array}{l}\text { Melakukan pencari produk Saus ABC } \\
\text { di dalam form pencarian, dengan } \\
\text { mengisi Id", "Nama Produk", "Harga } \\
\text { Beli", "Stock", "Harga jual", "Order } \\
\text { Quantity". }\end{array}$ & $\begin{array}{l}\text { Sistem menampilkan Hasil pencarian dengan } \\
\text { keluaran "Produk belum dimasukkan" dan } \\
\text { Product yang dicari tidak dapat ditemukan, } \\
\text { karena product tersebut belum dimasukkan ke } \\
\text { dalam form transaksi masuk atau form transaksi } \\
\text { keluar }\end{array}$ \\
\hline
\end{tabular}

\section{Hasil dan pembahasan}

Pengujian dilakukan pada aplikasi manajemen stok opname minimarket dengan tujuan untuk mengetahui kekurangan yang ada pada sistem sebelum digunakan oleh pengguna. Hasil dari pengujian jika ditemukan kelemahan dalam sistem maka pengguna bisa mengembangkan pada bagian tersebut yang dianggap lemah. Pada hasil pengujian terdapat tabel test case yang berfungsi untuk menyimpulkan apakah sistem berhasil dalam pengujian atau tidak. Pengujian akan dilakukan dengan metode Black Box berbasis Equivalence Partitions.

Tabel 4. Hasil Pengujian

\begin{tabular}{|c|c|c|c|c|}
\hline Id & Deskripsi pengujian & Hasil yang diharapkan & Hasil Pengujian & Status \\
\hline
\end{tabular}




\begin{tabular}{|c|c|c|c|c|}
\hline A001 & $\begin{array}{l}\text { Mengisi nama user: } \\
\text { root \& password: root } \\
\text { pada server MySQL }\end{array}$ & $\begin{array}{l}\text { Sistem menerima dan aplikasi } \\
\text { akan terbuka, dan } \\
\text { menampilkan tampilan home }\end{array}$ & $\begin{array}{l}\text { Aplikasi dapat terbuka } \\
\text { dengan normal dan } \\
\text { muncul tampilan Home }\end{array}$ & Sesuai \\
\hline A002 & $\begin{array}{l}\text { Mengisi nama user : } \\
\text { rizkyprasetyoadi707@ } \\
\text { gmail.com\& pasword : } \\
\text { apaajaboleh }\end{array}$ & $\begin{array}{l}\text { Sistem akan menolak dan } \\
\text { menampilkan pemberitahuan } \\
\text { "nama user dan Password } \\
\text { tidak cocok", aplikasi tidak } \\
\text { akan terbuka }\end{array}$ & $\begin{array}{l}\text { Aplikasi tidak dapat } \\
\text { dibuka dan muncul pop } \\
\text { up "aplication error" } \\
\text { "silahkan cek kembali } \\
\text { user dan pasword anda". }\end{array}$ & Sesuai \\
\hline A003 & $\begin{array}{l}\text { Mengkosongkan User } \\
\text { dan Password pada } \\
\text { server MySQL lalu } \\
\text { melaunching aplikasi }\end{array}$ & $\begin{array}{l}\text { Sistem akan menerima dan } \\
\text { menampilkan tampilan home, } \\
\text { meskipun user \& pasword } \\
\text { dikosongkan }\end{array}$ & $\begin{array}{l}\text { Aplikasi dapat terbuka } \\
\text { dengan normal dan } \\
\text { muncul tampilan Home }\end{array}$ & Sesuai \\
\hline B001 & $\begin{array}{l}\text { Memasukkan transaksi } \\
\text { barang masuk dengan } \\
\text { "Produk Indomie } \\
\text { Goreng pada kolom } \\
\text { form, mengisi } \\
\text { kuantitas barang "1" \& } \\
\text { harga jual satuan "Rp. } \\
\text { 3500". }\end{array}$ & $\begin{array}{l}\text { Produk Indomie Goreng } \\
\text { akan muncul pada kolom } \\
\text { transaksi masuk. Dengan } \\
\text { harga jual satuan "Rp. } 3500 " \\
\text { Dan jumlah kuantitas "1". }\end{array}$ & $\begin{array}{l}\text { Muncul "Produk } \\
\text { Indomie Goreng beserta } \\
\text { harga jual satuan dan } \\
\text { jumlah kuantitas sesuai } \\
\text { dengan pemasukan pada } \\
\text { form transaksi barang } \\
\text { masuk. }\end{array}$ & Sesuai \\
\hline B002 & $\begin{array}{l}\text { Mengosongkan } \\
\text { transaksi barang keluar } \\
\text { kedalam form yang } \\
\text { sama dengan } \\
\text { sebelumnya. (masih } 1 \\
\text { form }\end{array}$ & $\begin{array}{l}\text { Produk Indomie Goreng } \\
\text { tidak akan muncul pada } \\
\text { kolom transaksi keluar. } \\
\text { Meskipun masih dalam } 1 \\
\text { form yang sama dengan } \\
\text { transaksi masuk. } \\
\text { Kuantitas produk akan } \\
\text { otomatis menulis angka " } 0 \text { ", } \\
\text { pada transaksi barang keluar. }\end{array}$ & $\begin{array}{l}\text { Form transaksi keluar } \\
\text { yang ditampilkan } \\
\text { kosong karena produk } \\
\text { belum dimasukkan ke } \\
\text { dalam form transaksi } \\
\text { keluar dan muncul } \\
\text { kuantitas dengan angka } \\
\text { "0" }\end{array}$ & Sesuai \\
\hline $\mathrm{C} 001$ & $\begin{array}{l}\text { Melakukan } \\
\text { pencari produk } \\
\text { Saus ABC di } \\
\text { dalam form } \\
\text { pencarian, dengan } \\
\text { mengisi } \\
\text { Id",'Nama } \\
\text { Produk",'Harga } \\
\text { Beli",,'Stock",,'H } \\
\text { arga jual",,'Order } \\
\text { Quantity". }\end{array}$ & $\begin{array}{l}\text { Sistem menampilkan } \\
\text { Hasil pencarian dengan } \\
\text { keluaran "Produk belum } \\
\text { dimasukkan" dan product } \\
\text { yang dicari tidak dapat } \\
\text { ditemukan, karena } \\
\text { product tersebut belum } \\
\text { dimasukkan ke dalam } \\
\text { form transaksi masuk atau } \\
\text { form transaksi keluar }\end{array}$ & $\begin{array}{l}\text { Muncul pop up dari } \\
\text { aplikasi yang } \\
\text { bertuliskan "Produk } \\
\text { belum dimasukkan" }\end{array}$ & Sesuai \\
\hline
\end{tabular}

\section{Kesimpulan}

Pemeriksaan yang dilakukan untuk memastikan bahwa fungsi sistem bekerja dengan sebaik-baiknya dan memeriksa kesalahannya. Dalam menentukan tingkat akurasi agar semua parameter akurasi yang terkait seperti tahapan kerahasiaan, integritas data, dan ketersediaan data dapat sesuai dengan kebutuhan, maka diperlukannya proses pengujian metode lain guna sebagai nilai standar keamanan informasi, selain menggunakan metode Equivalence Partitions. Setelah dilakukan pengujian Black Box berbasis

Equivalence Partioning terhadap Aplikasi manajemen stok opname minimarket dapat disimpulkan dalam pengujian tidak ditemukan kesalahan. Penelitian ini telah berhasil merancang bangun Aplikasi manajemen stok opname minimarket menggunakan Bahasa pemprograman PHP dan database MySQL. Dengan Aplikasi manajemen stok opname minimarket pramuniaga atau petugas gudang dapat mengelola, 
menginformasikan kegiatan-kegiatan stock opname yang dimiliki maupun akan dilaksanakan kepada supervisor secara lebih luas.

\section{Saran}

Sistem informasi ini dapat dikembangkan lagi dengan menambahkan informasi-informasi lainnya yang relevan terkait aktivitas Stock Opname yang ada pada Minimarket K-Mart dan juga cakupan lokasinya dapat diperluas untuk berbagai minimarket yang ada di Indonesia.

\section{Referensi}

Hidayat, T., \& Muttaqin, M. (2018). Pengujian Sistem Informasi Pendaftaran dan Pembayaran Wisuda Online menggunakan Black Box Testing dengan Metode Equivalence Partitioning dan Boundary Value Analysis. Jutis (Jurnal Teknik Informatika), 6(1), 25-29.

Jaya, M. S., Gumilang, P., Wati, T., Andersen, Y. P., \& Desyani, T. (2019). Pengujian Black Box pada Aplikasi Sistem Penunjang Keputusan Seleksi Calon Pegawai Negeri Sipil Menggunakan Teknik Equivalence Partitions. Jurnal Informatika Universitas Pamulang, 4(4), 131136.

Krismadi, A., Lestari, A. F., Pitriyah, A., Mardangga, I. W., Astuti, M., \& Saifudin, A. (2019). Pengujian Black Box berbasis Equivalence Partitions pada Aplikasi Seleksi Promosi Kenaikan Jabatan. Jurnal Teknologi Sistem Informasi dan Aplikasi, 2(4), 155-161.

Mustaqbal, M. S., Firdaus, R. F., \& Rahmadi, H. (2015). Pengujian Aplikasi Menggunakan Black Box
Testing Boundary Value Analysis (Studi Kasus : Apilkasi Prediksi Kelulusan SNMPTN). Jurnal Ilmiah Teknologi Informasi Terapan, 1(3), 31-36.

MZ, M. K. (2016). Pengujian Perangkat Lunak Metode Black-Box Berbasis Equivalence Partitions Pada Aplikasi Sistem Informasi Sekolah. Jurnal Mikrotik, 2-8.

Ningrum, F. C., Suherman, D., Aryanti, S., Prasetya, H. A., \& Saifudin, A. (2019). Pengujian Black Box pada Aplikasi Sistem Seleksi Sales Terbaik Menggunakan Teknik Equivalence Partitions. Jurnal Informatika Universitas Pamulang, 4(4), 125-130.

Nurudin, M., Jayanti, W., Saputro, R. D., Saputra, M. P., \& Yulianti, Y. (2019). Pengujian Black Box pada Aplikasi Penjualan Berbasis Web Menggunakan Teknik Boundary Value Analysis. Jurnal Informatika Universitas Pamulang, 4(4), 143-148.

Saifudin, A., \& Yulianti, Y. (2020). Dimensional Reduction on Cross Project Defect Prediction. Journal of Physics: Conference Series. 1477, p. 022030. Tangerang: IOP Publishing. doi:10.1088/1742-6596/1477/3/032011

Syaban, R. M., \& Bunyamin, H. (2015). Pengembangan Sistem Informasi Pengelolaan Surat Masuk dan Keluar Berbasis Web di Dinas Sosial Tenaga Kerja dan Transmigrasi Kabupaten Garut Menggunakan Framework PHP. Jurnal Algoritma, 12(2), 301-311. 